\title{
Analisis Sosial Budaya terkait Pernikahan Usia Dini di Kepulauan Selayar
}

\section{Analysis of Social Culture Related to Early Marriage at Selayar Island}

\author{
Andi Pramesti Ningsih ${ }^{1 *}$, Suriah ${ }^{1}$, Muhammad Syafar ${ }^{1}$, Masyitha Muis ${ }^{2}$, Sukri $^{3}$, Muhammad
} Tahir Abdullah ${ }^{4}$

${ }^{1}$ Promosi Kesehatan, Fakultas Kesehatan Masyarakat, Universitas Hasanuddin

${ }^{2}$ Kesehatan dan Keselamatan Kerja, Fakultas Kesehatan Masyarakat, Universitas Hasanuddin

${ }^{3}$ Administrasi dan Kebijakan Kesehatan, Fakultas Kesehatan Masyarakat, Universitas Hasanuddin

${ }^{4}$ Kesehatan Reproduksi, Fakultas Kesehatan Masyarakat, Universitas Hasanuddin

*Korespondensi penulis:

ningsihpramesti@gmail.com
Diterima (Recieved)

Direvisi (Revised)

Diterima untuk diterbitkan (Accepted)
: 15 Agustus 2020

: 9 Oktober 2020

: 24 Desember 2020

\section{ABSTRAK}

Latar Belakang. Pernikahan di usia dini menimbulkan dampak negatif terhadap remaja baik dalam aspek fisik, psikologis dan biologis. Pernikahan di usia dini sangat erat kaitannya dengan tradisi yang ada di lingkungan masyarakat seperti perjodohan.

Tujuan. Penelitian ini bertujuan untuk mengeksplorasi sosial budaya terkait pernikahan usia dini di Pulau Selayar.

Metode. Penelitian ini menggunakan metode kualitatif dengan pendekatan fenomenologi deskriptif. Informan terdiri termasuk remaja, orang tua, penyedia kesehatan, dan kepala komunitas. Data dikumpulkan menggunakan wawancara mendalam dan diskusi kelompok terarah sesuai dengan tujuan penelitian. Data dianalisis dengan menggunakan analisis domain.

Hasil. Tiga domain utama yang ditemukan dalam penelitian ini terkait pernikahan usia dini adalah: (1) perjodohan merupakan faktor yang mendukung terjadinya pernikahan di usia dini (2) dukungan sosial yang diberikan masyarakat terhadap pernikahan di usia dini karena adanya tradisi perjodohan yang berlaku dalam lingkungan masyarakat (3) pengetahuan yang dimiliki masyarakat dan remaja masih kurang mengenai dampak pernikahan usia dini.

Kesimpulan. Sosial budaya yang ada di masyarakat dapat digunakan sebagai salah satu pendekatan untuk menurunkan angka pernikahan di usia dini.

Kata Kunci: dukungan sosial, pernikahan di usia dini, pengetahuan, perjodohan, sosial budaya

\begin{abstract}
Background. Marriage at an early age has a negative impact on adolescents in physical, psychological, and biological aspects. Marriage at an early age is closely related to traditions in society such as arranged marriage.

Objective. This study aimed to to explore the socio-culture related to early marriage on Selayar Island.

Method. This study used a qualitative method with a descriptive phenomenology approach. Informants include youth, parents, health providers, and community heads. Data were collected using in-depth interviews and focus group discussions following the research objectives. Data were analyzed using domain analysis.

Results. Three main domains found in this study related to early marriage are: (1) arranged marriage is a factor that supports early marriage (2) social support from the community supporting marriage at an early age because of the prevailing arranged marriage tradition in the society (3) the knowledge possessed by the community and adolescents is still lacking about the impact of early marriage

Conclusion: Social culture in the community can be an approach to reducing early marriage.
\end{abstract}

Keywords: social support, early marriage, arranged marriage, knowledge, socio-culture

\section{LATAR BELAKANG}

Pernikahan di usia dini adalah pernikahan sebelum usia 18 tahun baik bagi anak laki-laki atau perempuan. Proses perkawinan dilakukan secara formal oleh tokoh masyarakat yang di- 
akui atau melalui kantor urusan agama atau informal dengan hidup Bersama. ${ }^{1}$ Pernikahan dini di pedesaan hampir sepertiga lebih tinggi daripada di daerah perkotaan. ${ }^{2}$ Penelitian di Pulau Selayar menemukan 65\% kasus pernikahan pertama di bawah usia 18 tahun. ${ }^{3}$

Dampak dari pernikahan usia dini dapat dilihat dari beberapa aspek seperti kesehatan sosial, dan psikologi. Rendahnya kesadaran atas pengetahuan kesehatan, pertumbuhan dan perkembangan fisik menyebabkan wanita yang mengandung anak di usia dini berisiko lebih tinggi terhadap masalah kesehatan ibu, cacat dan kematian, serta risiko bagi bayi baru lahir. Selain itu, pada pasangan pernikahan usia dini belum memahami hak dan kewajiban dalam rumah tangga secara baik karena belum ada kematangan fisik maupun mental. ${ }^{4}$

Ada beberapa faktor yang mempengaruhi pernikahan dini, baik keputusan pribadi ataupun pengaruh budaya. ${ }^{5}$ Keputusan pribadi dipengaruhi oleh keluarga, lingkungan dan kebiasaan di masyarakat. ${ }^{6}$ Pengambilan keputusan untuk menikah dini berhubungan erat dengan perjodohan. Semakin tinggi budaya perjodohan, maka semakin besar kemungkinan anak menikah di usia kurang dari 18 tahun. Hal ini berhubungan dengan peran masyarakat, semakin tinggi tingkat dukungan masyarakat, maka remaja cenderung memutuskan untuk menikah $<18$ tahun. $^{7}$

Menurut tokoh masyarakat meskipun anak saat ini berat untuk menyetujui perjodohan, namun mereka harus menerima perjodohan ketika usia telah dianggap siap untuk menikah dan belum menemukan pasangan. Hal ini dilakukan untuk menghindari anak menjadi perawan tua. Pernikahan sebagai cara yang dilakukan sebagai penutup malu dari penilaian masyarakat. $^{8}$

Sistem perkawinan di masyarakat Selayar memiliki kepercayaan kuat pada pasangan ideal, yaitu pindu (sepupu dua kali) dan pinta (sepupu tiga kali). Hal ini menciptakan budaya yang disebut lappasitanraang (perjodohan pada anak usia dini). ${ }^{9}$ Namun, hingga saat ini, belum ada penelitian tentang pernikahan dini di Pulau Selayar. Oleh karena itu, penelitian ini ingin mengeksplorasi sosial budaya yang mempengaruhi terjadinya pernikahan usia dini.

\section{METODE}

Penelitian kualitatif ini menggunakan pendekatan fenomenologi. Informan dalam penelitian ini dipilih secara purposive sampling berdasarkan kriteria yang telah ditentukan. Adapun informan dalam penelitian ini adalah empat remaja yang menikah di usia dini, empat remaja yang belum menikah, dua orangtua remaja, seorang petugas kesehatan dan seorang tokoh masyarakat.

Data dianalisis menggunakan analisis domain yaitu cara menemukan domain dari situasi sosial yang diteliti. Analisis domain memiliki 9 tipe hubungan semantik berupa jenis, ruang, sebab-akibat, rasional, lokasi, cara, fungsi, urutan dan atribut. Data yang didapatkan akan dikelompokkan berdasarkan hubungan semantik dalam analisis domain ${ }^{10}$. Fokus analisis penelitian yaitu sebab-akibat.

Pada penelitian ini, uji keabsahan data dilakukan dengan menggunakan kredibilitas dan transferabilitas. Kredibilitas dengan cara merekam hasil wawancara tersebut, hasil rekaman menjadi bukti keabsahan data yang diteliti dan bukan hasil rekayasa peneliti. Wawancara sebagai upaya mengkonstruksikan kejadian yang dialami informan. Dengan melakukan observasi memungkinkan upaya untuk memperoleh keyakinan tentang keabsahan data penelitian tercapai. Sementara untuk transferabilitas dilakukan dengan konfirmasi ulang kepada informan mengenai informasi yang diberikan. Lalu menguraikan secara rinci hasil temuan yang didapat dalam bentuk naratif. Selanjutnya pembahasan atas hasil penelitian menggunakan jurnal dan lite-ratur yang sesuai dengan topik penelitian.

Sebelum pengumpulan data, persetujuan etik telah disetujui oleh Komite Etik Fakultas Kesehatan Masyarakat Universitas Hasanudin dengan Nomor Protokol 7120082020 
Tabel 1. Karakteristik Informan

\begin{tabular}{|c|c|c|c|}
\hline No. & Informan & Kriteria Informan & Metode Pengumpulan Data \\
\hline 1. & $\begin{array}{l}\text { Remaja dengan pernikahan } \\
\text { usia dini } \\
\text { (informan utama) }\end{array}$ & $\begin{array}{l}\text { 1. Remaja yang telah menikah pada usia sekolah } \\
\text { 2. Pendidikan terakhir SMP atau SMA } \\
\text { 3. Remaja yang menikah dengan sesama remaja } \\
\text { 4. Remaja yang menikah dengan orang yang } \\
\text { lebih tua } \\
\text { 5. Remaja laki-laki dan perempuan }\end{array}$ & Wawancara Mendalam \\
\hline 2. & $\begin{array}{l}\text { Remaja yang tidak } \\
\text { melakukan pernikahan usia } \\
\text { dini } \\
\text { (informan pendukung) }\end{array}$ & $\begin{array}{l}\text { 1. Remaja yang masih duduk di bangku SMP } \\
\text { atau SMA } \\
\text { 2. Remaja yang menolak menikah di usia dini } \\
\text { 3. Remaja laki-laki dan perempuan }\end{array}$ & $\begin{array}{l}\text { Wawancara mendalam dan } \\
\text { FGD }\end{array}$ \\
\hline 3. & $\begin{array}{l}\text { Orang tua } \\
\text { (informan pendukung) }\end{array}$ & $\begin{array}{l}\text { 1. Orang tua yang memiliki anak yang menikah } \\
\text { di usia dini } \\
\text { 2. Orang tua yang memiliki anak yang berusia } \\
\text { dini }\end{array}$ & Wawancara Mendalam \\
\hline 4. & $\begin{array}{l}\text { PLKB } \\
\text { (informan pendukung) }\end{array}$ & $\begin{array}{l}\text { Petugas yang memberikan penyuluhan mengenai } \\
\text { keluarga berencana }\end{array}$ & Wawancara Mendalam \\
\hline
\end{tabular}

Tabel 2. Domain dan Sub Domain dari Sosial Budaya terkait Pernikahan di Usia Dini

\begin{tabular}{lll}
\hline \multicolumn{1}{c}{ Domain } & \multicolumn{1}{c}{ Sub domain } \\
\hline Penyebab Pernikahan & - Perjodohan \\
Tanggapan Masyarakat & - Pergaulan remaja \\
& - Mendukung pernikahan di usia dini \\
Pengetahuan & - Tidak mendukung pernikahan di usia dini \\
& - Mengetahui dampak pendidikan, ekonomi dan psikologis dari \\
& & pernikahan di usia dini \\
& - Tidak mengetahui dampak biologis dari pernikahan di usia dini \\
\hline
\end{tabular}

\section{HASIL}

Hasil wawancara dianalisis dengan menggunakan analisis domain. Pernyataan informan dalam wawancara mendalam dan focus group discussion dianalisis dan dicocokkan satu sama lain sehingga saling mendukung informasi yang ditemukan. Tiga domain utama ditemukan dalam penelitian ini.

Perjodohan adalah jenis ikatan pernikahan dimana pengantin pria dan wanitanya dipilih oleh pihak ketiga dan bukan oleh satu sama lain. Pernikahan yang terjadi karena perjodohan seringkali bukan keinginan pasangan yang menikah. Namun, hal ini dikarenakan desakan orangtua atau tokoh masyarakat yang ada di sekitarnya tanpa memperhatikan usia pasangan yang menikah.

Sebagian besar informan yang menikah di usia dini mengatakan bahwa mereka menerima pernikahan di usia dini karena perjodohan. Mereka mengetahui perjodohan setahun sebelum pernikahan dan belum mengenal calon pasangannya.
"Saya tidak kenal dengan dia. Kami diperkenalkan satu sama lain setahun sebelum menikah dan saya masih merasa bingung” (AR, Remaja)

"Masih ada hubungan keluarga dan kerabat. Orangtua yang memilih pasangan dan saya tidak memiliki keberanian untuk menolak" (RI, Remaja)

Informan mengatakan bahwa mereka tidak dapat mengatakan tidak saat orangtua meminta untuk menikah. Mereka percaya bahwa hal ini adalah caranya untuk menjadi anak berbakti.

Hal ini juga didukung dengan informasi yang diberikan oleh tenaga kesehatan bahwa perjodohan menjadi salah satu faktor yang menyebabkan pernikahan usia dini di Kepulauan Selayar.

"Iya, Sepertinya di kota sudah tidak ada perjodohan, tetapi di desa masih ada. Beberapa yang menikah di usia dini bukan karena keinginan anaknya, tetapi permintaan orangtuanya" (TI, Petugas Kesehatan)

Tokoh masyarakat mengakui adanya pernikahan di usia dini dan juga alasan lain yang menyebabkan pernikahan di usia dini di sekitar lingkungan mereka. 
"Perjodohan itu biasa terjadi. Hal yang normal menurut saya ketika orangtua ingin yang terbaik untuk anaknya. Hanya itu yang bisa kita berikan kepada anak. Akan tetapi, untuk saat ini sudah banyak yang berbeda juga, banyak anak-anak yang menikah karena berkenalan dengan orang-orang lewat handphone. Seringkali, mereka sudah menentukan pilihan sendiri untuk menikah dengan siapa. Namun, sampai saat ini tidak bisa dipungkiri bahwa perjodohan masih kerap terjadi meskipun tidak sebanyak dulu. Perjodohan itu bertujuan untuk menjaga nama baik keluarga" (MA, Tokoh Masyarakat)

Perjodohan yang terjadi saat ini sudah berkurang jika dibandingkan di beberapa tahun yang lalu. Namun, perjodohan tersebut masih sering dilakukan oleh keluarga yang memegang teguh perjodohan dan ingin anaknya mendapatkan pasangan yang terbaik. Saat ini penyebab pernikahan di usia dini bukan hanya perjodohan namun juga kemajuan teknologi.

Dukungan sosial merupakan bentuk dukungan yang didapatkan individu dari orang lain baik dari keluarga, tetangga maupun teman. Dukungan sosial yang didapatkan bisa berupa tanggapan negatif atau positif. Bentuk dukungan akan mempengaruhi keputusan individu untuk menikah di usia dini.

Informan yang menikah di usia dini karena perjodohan mengatakan bahwa orangtua mendukung pernikahannya. Dukungan yang didapatkan seperti persetujuan menikah dan bantuan keuangan.

“Orangtua pasti setuju karena pernikahan itu keinginan mereka. Setelah menikah, orangtua juga masih memberikan uang karena saya belum bekerja" (AR, Remaja)

Namun, informan yang menikah atas pilihan sendiri kesulitan mendapatkan dukungan dari orangtuanya.

"Pada awalnya, orangtua tidak menyetujui pernikahan saya. Tapi saya terus mencoba untuk meyakinkan orangtua bahwa saya sudah bisa bertanggung jawab dan siap untuk menjalani pernikahan" (RI, Remaja)

Orangtua juga mengungkapkan dukungan mengenai pernikahan di usia dini sebagai berikut:

"Pernikahan yang terjadi itu untuk menghindari pendapat para tetangga. Anak saya sudah memiliki pacar dan tidak bagus jika diliat sering berduaan. Sehingga lebih baik untuk dinikahkan" (SH, Orangtua)
"Masih tetap dibantu untuk kebutuhan sehari-hari. Tidak mungkin untuk melepas secara penuh karena bagaimanapun juga, dia anak saya. Waktu awal menikah, saya biarkan dia mengurus segala sesuatunya sendiri tapi akhirnya saya bantu juga" (HR, Orangtua)

Selain itu, informan juga mengungkapkan pendapat masyarakat di sekitarnya:

"Kalau tetangga sudah biasa memberikan pendapat bahwa anak saya hamil. Hal itu yang menjadi alasan mengapa dia cepat menikah. Sudah hal biasa kalua gosip tetangga” (TI, Remaja)

"Beberapa teman saya juga menikah karena dijodohkan. Jadi menikah di usia dini sudah menjadi kebiasaan di sini. Hal biasa menurut masyarakat", (AO, Remaja)

Hal ini menunjukkan bahwa dukungan sosial yang didapatkan tergantung pada tradisi yang ada di lingkungan masyarakat dan alasan informan menikah. Informan yang berada di lingkungan dengan tradisi perjodohan yang masih berlaku akan mendapatkan dukungan dalam menikah di usia dini. Namun, informan yang berada di lingkungan yang tidak lagi memegang teguh prinsip pernikahan di usia dini akan menerima dan tangapan negatif dari lingkungan seperti kehamilan di luar pernikahan.

Tingkat pendidikan yang rendah atau pengetahuan orang tua, anak dan masyarakat akan mempengaruhi pola pikir mereka dalam keputusan untuk menikahkan anaknya yang masih di bawah umur. Tingkat pendidikan juga mempengaruhi tingkat pengetahuan yang dimiliki terkait dampak dari pernikahan di usia dini. Pengetahuan yang terbatas terkait dampak negatif cenderung mendukung terjadinya pernikahan di usia dini.

Remaja dan orangtua mengetahui bahwa pernikahan di usia dini berdampak pada kehidupan yang dijalani seperti pendidikan, psikologi dan ekonomi. Hal yang paling dirasakan terkait dampaknya adalah dampak terhadap pendidikan, seperti yang diungkapkan berikut ini:

"Putus sekolah dan tidak bisa meraih cita-cita” (KA, Remaja)

"Harus berhenti sekolah karena harus tinggal di rumah dan menyelesaikan pekerjaan sebagai istri di rumah” (RL, Remaja) 
Informan lain yang menikah di usia dini mengungkapkan dampak terhadap psikologi dan ekonomi setelah menikah.

"Saya masih muda dan labil. Terkadang bertengkar karena salah paham dan hal lain sejenisnya" (PI, Remaja)

"Untuk kebutuhan belanja masih ditanggung orangtua, berhubung masih belum bekerja" (LA, Remaja)

Hal tersebut menunjukkan jika remaja menyadari bahwa usia yang masih muda dalam menikah rentan dengan kesalahpahaman dan ketergantungan ekonomi kepada orangtua.

Informan tidak mengungkapkan dampak biologis. Hal ini memperlihatkan bahwa informan belum menyadari dampak biologis dari menikah di usia dini. Sementara, petugas kesehatan mengatakan bahwa mereka telah memberikan pendidikan kesehatan.

"Kita sudah melakukan sosialisasi dan penyuluhan mengenai dampak pernikahan di usia dini. Misalnya kalau terjadi kehamilan kemudian melahirkan maka akan rentan terjadi pendarahan. Organ dalam bagian reproduksi juga masih belum siap untuk melakukan hubungan suami istri. Selain itu, melahirkan di usia muda berpotensi untuk mengakibatkan terjadinya kanker di kemudian hari" (TI, Petugas Kesehatan)

Berdasarkan informasi tersebut diketahui bahwa meskipun petugas kesehatan telah melakukan penyuluhan kesehatan, namun informasi akan dampak pernikahan usia dini belum dipahami dengan baik oleh masyarakat dan remaja.

\section{PEMBAHASAN}

Sosial budaya terkait perjodohan sering menjadi alasan terjadinya pernikahan dini. Sosial budaya merupakan sebuah tradisi yang berkembang di lingkungan masyarakat dan bertahan dari waktu ke waktu. ${ }^{11}$ Anak-anak yang berasal dari keluarga yang memegang prinsip perjodohan memiliki peluang pernikahan yang lebih besar dengan pernikahan yang diatur. Selain itu, anak-anak yang belum menikah dianggap sebagai bongganna (penutupan kehormatan keluarga). ${ }^{12}$

Orangtua ingin anaknya menikah dengan orang yang tepat sesuai pilihan mereka. Keinginan orangtua inilah yang menjadikan perjodohan kerap terjadi bahkan di usia yang masih muda. Mereka tidak ingin anaknya salah dalam memilih pasangan. Hal ini didukung oleh penelitian yang telah dilakukan sebelumnya bahwa orang tua menjodohkan anaknya karena orang tua sudah memiliki pilihan yang tepat untuk anak-anak mereka. ${ }^{13}$ Alasan lain, beberapa penelitian yang mengatakan bahwa pernikahan dini berhubungan dengan ketakutan keluarga akan anak perempuan menjadi perawan tua dan melakukan hubungan seks pranikah. ${ }^{14,15}$ Karena itu, pernikahan dini digunakan sebagai solusi untuk menjaga kehormatan. ${ }^{12}$

Remaja yang menikah di usia dini karena adanya dukungan dari lingkungan mereka. Remaja telah terbiasa melihat teman seusia mereka yang juga menikah di usia dini dan dipasangkan dengan keluarganya sendiri. Individu menjadi sangat takut dan tidak cukup berani untuk membuat keputusan sendiri. ${ }^{16}$ Mayoritas remaja berpikir bahwa pernikahan sebelum 20 tahun adalah normal karena dukungan dari keluarga dan juga persepsi masyarakat mengenai anak-anak yang berpacaran harus dinikahkan sesegara mungkin. 17,18

Kejadian perjodohan dan tingginya tingkat dukungan sosial dalam penelitian ini dipengaruhi oleh tingkat pengetahuan masyarakat dan remaja yang masih kurang. Hasil penelitian menunjukkan bahwa kesadaran mereka terkait dampak negatif hanya terbatas pada dampak yang terlihat seperti putus sekolah dan kendala ekonomi. Namun belum menyadari bahwa ada dampak yang lebih besar kedepannya yaitu dampak biologis.

Pernikahan membutuhkan pengetahuan yang cukup tentang seksualitas, kemampuan untuk memenuhi kebutuhan fisik dan spiritual anak-anak mereka dan terutama usia yang tepat untuk menikah. Pernikahan dini dapat memengaruhi psikologi dan biologis mereka (kesehatan reproduksi). ${ }^{19}$ Pengetahuan remaja mengenai pernikahan di usia dini terbatas terutama dampak biologis. ${ }^{20,21}$ Hal ini yang mendukung tradisi perjodohan sebagai salah satu budaya yang terus dipertahankan oleh tokoh masyarakat.

\section{KESIMPULAN}

Hasil penelitian ini menunjukkan bahwa tiga domain utama dari variabel keyakinan normatif yang mempengaruhi pernikahan dini 
yaitu perjodohan, dukungan sosial, dan pengetahuan.

\section{SARAN}

Petugas kesehatan perlu melakukan upaya preventif dan promotif dengan pendekatan kepada tokoh masyarakat untuk meningkatkan pengetahuan terkait dampak pernikahan di usia dini sehingga tradisi perjodohan di usia dini dapat dicegah.

\section{UCAPAN TERIMA KASIH}

Peneliti berterimakasih kepada pihakpihak yang telah menjadi responden dari penelitian ini. Khususnya kepada orang tua dan remaja yang melakukan/tidak melakukan pernikahan di usia dini yang berasal dari Kecamatan Bontomatene, dan Penyuluh Keluarga Berencana Kabupaten Kepulauan Selayar.

\section{DAFTAR REFERENSI}

1. United Nations Emergency Children's Fund. Child marriage. https://www.unicef.org/rosa/what-wedo/child-protection/child-marriage. Published 2019.

2. Badan Pusat Statistik. Perkawinan Usia Anak di Indonesia. Br J Psychiatry.

2017;112(483):211-212. doi:10.1192/bjp.112.483.211-a

3. Mappigau P., Nursyamsi I., Upe JA. MA. Study of marriage events of early-age women between Mainland and Coastal Islands, South Sulawesi. Acta Sci Nutr Heal. 2019;3(5):219-227.

4. Ahmed, S., Alia, M., Shamoon, Khan S. Psychological impact evaluation of early marriages. Int J Endorsing Heal Sci Res. 2014;1(2).

5. Sahara N., Idris. PD. Faktor-faktor yang mempengaruhi keputusan wanita menikah di Sumatera Barat. Ecogen. 2018;1(3):160-164.

6. Jilyana., Suriah., Abdullah MT., Nasir S., Jafar N. MA. Personal references \& personal autonomy adolescents to genre concept. Int J Adv Res. 2019;7(7):254-259.

7. Suhariyati, Haryanto, J., Probowati R. Faktor- faktor yang berhubungan dengan pengambilan keputusan pernikahan remaja di Kabupaten Bondowoso. J Penelit Kesehat Suara Forikes. 2019;10(4):285-289.
8. Afriani. Studi fenomenologi persepsi masyarakat terhadap pernikahan usia dini di lingkungan gernas kelurahan madatte. $\mathbf{J}$ Kesehat Masy. 2016;2(2).

9. Ahmadin. Nusa Selayar: Sejarah Dan Kebudayaan Masyarakat Di Kawasan Timur Nusantara. Makassar: Reyhan Intermedia; 2016.

10. Sugiyono. Metode Penelitian Kualitatif: Untuk Penelitian Yang Bersifat Eksploratif, Enterpretif, Interaktif Dan Konstruktif. Bandung: Alfabeta; 2018.

11. I A. Attitudes, Personality and Behavior. 2nd ed. New York: Open University Press; 2005.

12. NA B. Filosofi Nikah (Studi Perkawinan Orang Selayar). Makassar: Fahmis Pustaka; 2017.

13. Meiandayati R., Nirmala SA. SA. Kejadian pernikahan usia dini berdasarkan karakteristik dan sosial budaya di Desa Cipacing Kecamatan Jatinangor Kabupaten Sumedang Tahun 2014. J Sist Kesehat. 2015;1(2):76-83.

14. Workineh, Sileshi; Kibretb GDDG. Determinants Of early marriage among female children In Sinan District, Northwest Ethiopia. Heal Sci J. 2015;9(6):1-7.

15. Lowe M., Joof M. RB. Social and cultural factors perpetuating early marriage in Rural Gambia: an exploratory mix methods. F1000Research. 2020;1949(8).

16. S S. Psikologi Remaja. Jakarta: Rajawali Press; 2015.

17. Husna N., Demartoto A. RS. Factors Associated with early marri-age in Sleman. J Heal Promot Behav. 2016;1(2):87-98.

18. Nasrullah M., Zakar R., Zakar MZ., Abbas S., Safdar R., Shaukat M. et al. Knowledge and attitude towards child marriage practice among women married as children-a qualitative study in urban slums of Lahore, Pakistan. BMC Public Heal 2014;14(1148). 2014;14(1148).

19. Kabir M., Ghosh S. SA. Causes of early marriage and its effect on reproductive health of young mothers in bangladesh. Am J Appl Sci. 2019;16(9):289-297.

20. Ningsih AP., Suriah., Muis M., Syafar M., Sukri. AM. Adolescent's Perception and Severity Related to Early Marriage, in Selayar Island. Int J Multicult Multireligous Underst. 2020;7(4):132-139.

21. Yastirin P. Persepsi remaja tentang pernikahan usia anak. J Qual Women's Heal. 2019;2(1):43-49. 